\title{
Adolescent substance use: a two year population follow-up
}

\author{
HaRITH Swadi, Consultant Child Psychiatrist, Medway Health Authority, \\ 118 Maidstone Road, Chatham, Kent ME4 6DL
}

Exactly two years after a large survey of substance use among secondary school adolescents in London in 1987 (Swadi, 1988), a similar survey among a subsample using the same questionnaire was carried out. Of 242 second- and third-year pupils from one of the six schools in the original sample, 219 were available for the follow-up. In 1989 they were in the fourth and fifth years; the sexes were equally represented. The follow-up survey aimed to investigate the trends with respect to the prevalence of use of various drugs and to investigate the effect of the absence of a specific drug-prevention programme on such trends. Comparisons are also made with survey results from the fourth and fifth year at the same school in 1987.

\section{The study}

The survey was carried out using self-report anonymous questionnaires. The detailed methodology of the survey and the validity and reliability of self-reports in this field of research have been described elsewhere (Swadi, 1988, 1989). It is generally accepted that self-reports can give a reasonable profile of the extent and patterns of substance misuse in adolescents, although figures cannot be taken at their exact face value.

The school chosen for the follow-up study had average prevalence rates of substance use, social class and ethnic origin composition for the six schools in the 1987 study. The prevalence rate of 'ever used drugs' in the six schools of the original 1987 study ranged between $12 \%$ and $28 \%$, for 'ever used alcohol' it was 46-70\%, and for 'current' cigarette smoking it was $13-21 \%$. For this school the rates were $17 \%$, $70 \%$ and $20 \%$ respectively. The majority of pupils came from working-class families and only about $20 \%$ were from middle-class families. Two-thirds of the school population were of British origin. No specific prevention programme to deal with substance misuse had been implemented in the school over the two years.

\section{Findings}

There were no significant changes in sex distribution over the two years, nor in the age distributions. The fourth-and fifth-year pupils in 1989 had average ages of 14.9 and 15.1 years respectively.

Age may account for differences occurring within the follow-up population over the two years. Sharp increases in the use of drugs and in cigarette smoking occurred. In $1987,8 \%$ had at some time used drugs and $14 \%$ were regular smokers. In 1989 these figures were $21 \%$ and $40 \%$ respectively. Frequent alcohol use (once a week or more) rose from $5 \%$ to $18 \%$. Solvent and cannabis use rose significantly from $3 \%$ in 1987 for both substances to $7 \%$ and $15 \%$ respectively. This confirms the evidence from crosssectional studies involving multiple age cohorts in which it is suggested that the age at which adolescents are at risk of substance use is 13-15 years (Swadi, 1988, Newcomb \& O'Hare, 1988).

Comparing fourth- and fifth-year pupils examined in the original sample in 1987 to those followed up in the current study showed that only the rate for regular cigarette smoking had significantly increased in that age group over the two years $(28 \%$ in 1987 v. $40 \%$ in 1989). Thus, cigarette smoking, which is less likely to be susceptible to local variations, may be showing signs of increase among London adolescents.

Drug use and frequent alcohol use remained unchanged at around $20 \%$ for the former and $15 \%$ for the latter. The patterns of use generally showed no significant differences. There was no evidence to support media reports claiming an increase in cocaine use among adolescents, especially in its 'crack' form. In fact there was a tendency for a decrease in cocaine use. However, there was an unexpected increase in cannabis use but mainly among less frequent users (9\% in 1987 v. $15 \%$ in 1989$)$.

\section{Comment}

The results confirm the continuation of the unacceptably high rates of substance use among London adolescents. However, there is at least one promising sign. On the whole, except for cigarette smoking, the picture did not get worse. The question of whether drug and alcohol prevention programmes are necessary to prevent increases in their use can partly be answered by the fact that, despite the lack of such programmes at this school, the figures for 
fourth-and fifth-year pupils in 1987 did not get worse when compared to a similar group in 1989. However, those of cigarette smoking did. That may be partly a function of the absence of a prevention programme since there is already good evidence to suggest that anti-smoking education campaigns have a better success rate (Health Education Authority, 1987). On the other hand, major increases occurred between 1987 and 1989 within the follow-up population, suggesting that there may be a place for prevention programmes at an earlier age.

This follow-up, despite its limitations, is among the few that have been carried out in this country. It may represent the situation among London adolescents, but we cannot tell if it represents all UK adolescents, underlying the need for further nationwide surveys monitoring trends and allowing for better planning and provision of services for adolescent and adult substance misusers. After all, addicts most often start drug use in adolescence.

\section{References}

HeALTH EDUCATION AUtHORTTY (1987) Smoking Education for Teenagers Project. London: HEA.

NewCOMB, R. \& O'HARE, P. (1988) A Survey of Drug Use among Young People in South Sefton in 1987. South Sefton Health Authority.

Swadi, H. (1988) Drug and substance use among a population of 3,333 London adolescents. British Journal of Addiction, 83, 935-942.

-(1989) Epidemiological Aspects of Substance Misuse in a Population of London Adolescents. (M.Phil Dissertation). London University.

\title{
'Lillian' - a play on schizophrenia
}

\author{
SURINDER S. JoHL, Senior Psychiatrist, Launceston General Hospital, Launceston, \\ Tasmania, Australia
}

"Welcome to 'Lillian'. This is all about schizophrenia. Schizophrenia is an illness, a serious mental illness which affects one person in a hundred. It is an illness which causes strange thoughts and strange feelings. It leads to emotional disturbances and a withdrawal from the reality of the external world. Those who suffer from it withdraw into their own world, into an unreal world of fantasy. Often they are tormented by strange and frightening experiences. Some develop strange ideas and fear that they are persecuted. Others hear voices, see and feel things that are not there, though they are real to them. Sometimes it is difficult to understand them because their thoughts are jumbled. They may even feel that someone else is interfering with their minds. In time, some lose their ability to do their everyday activities and lose their drive and initiative but this is not laziness. They often become very anxious and have periods of depression. For many the ability to express their emotions is blunted and in others their behaviour is unusual. These experiences are all very real to them and sadly some never realise what is happening to them. Most do recover with treatment, understanding and support but often under stress, relapses occur. We ask for your understanding and support".

These were the opening statements of a play put on by the patients and staff of the Department of Psychiatry, of Launceston General Hospital, Launceston, a relatively small conservative city of 65,000 in Northern Tasmania. The results made history. It was the first full-length theatre production in the form of a rock musical on mental illness.

The idea sprang in the Day Centre when some patients expressed the wish and need of making the public aware of mental illness, and the special needs of the mentally ill. They were aware of the stigma they faced following admission to the local psychiatric unit and the difficulties thereafter. This was taken up by our occupational therapist, Michael Bishop, who had experience in directing and producing plays. He took the bold step of booking the theatre almost nine months ahead. A drama group was set up with interested patients and they related in their own words their experiences starting from the time their problems started, their admissions to hospital, and events thereafter. Many had been through bitter experiences as a result of their illness and had much to say. A theme developed and a story began.

Lillian is a 19-year-old college student working in a news-agency. She develops schizophrenia, is admitted to hospital, recovers with treatment and relapses when she experiments with cannabis, an all too 